\title{
Técnica inmunocitoquímica para evaluar la proliferación de células en cultivo por la incorporación de bromodeoxiuridina
}

\author{
Sonia Rahirant, Zayra Garavito, Hernán Hurtado \\ Laboratorio de Neurociencias, Instituto Nacional de Salud, Santa Fe de Bogotá, D.C., Colombia. \\ Para evaluar la proliferación in vitro de células, se estandarizó una técnica inmunocitoquímica \\ no radioactiva, fácil de manejar, más rápida y segura que permite detectar la bromodeoxiuridina \\ (BrdU) incorporada en las células que entran en fase S. Durante la estandarización de la \\ técnica inmunocitoquímica con peroxidasa, se usaron varios tipos celulares y se obtuvieron \\ resultados similares. Brevemente, se realiza una incubación con BrdU durante 48 horas y \\ luego, se procesa el material celular para una inmunocitoquímica convencional que tiene \\ como paso adicional la desnaturalización del $\mathrm{ADN}$ con $\mathrm{HCl}$ previa a la incubación con el \\ anticuerpo primario anti-BrdU. Como cromógeno se usó la DAB (diaminobenzidina) o el AEC \\ (aminoetilcarbazol). El procedimiento utilizado permite ver una tinción específica para núcleos \\ en células que entran en fase $S$ y permite evaluar rápidamente el porcentaje de células que \\ están proliferando en el cultivo.
}

Palabras clave: inmunocitoquímica, bromodeoxiuridina, cultivo celular, células de Schwann, proliferación celular.

\begin{abstract}
Description of an immunocytochemical evaluation technique for in vitro cell proliferation by bromodeoxiuridine incorporation

In order to evaluate in vitro cell proliferation, an inmunocytochemistry non radioactive, easy, safe and fast technique, which detects bromodeoxiuridine taken by entering in S phase cells, was standardized. Several kinds of cells were used for peroxidase-inmunocytochemistry technique standardization. In all cases the same results were obtained. Briefly, BrdU was incubated for 48 hours, then cell cultures were processed for standard inmunocytochemistry. An additional step for DNA denaturalization using $\mathrm{HCl}$, before antibody incubation, was included. DAB (di-amino-benzidine) or AEC (amino-ethyl-carbazol) were used As chromogens. This procedure results in a specific nuclei staining on proliferating cells and it allows quick evaluation of cell proliferation on cultures.
\end{abstract}

Key words: inmunocyitochemistry, bromodeoxiuridine, cell culture, Schwann cells, cellular proliferation.

La mayoría de las técnicas utilizadas hasta hace poco tiempo para determinar la proliferación celular, emplean sustancias radioactivas de manejo peligroso que requieren tiempos prolongados para la evaluación final de los resultados, como es el caso de la incorporación de timidina tritiada $(1,3)$. Así, se han desarrollado técnicas no radioactivas fáciles de utilizar y con un menor riesgo al ser ejecutadas. La

\section{Correspondencia:}

hhurtado@hemagogus.ins.gov.co

Recibido: 17/01/00; aceptado: 07/04/00 incorporación de bromodeoxiuridina (BrdU) y su detección por inmunocitoquímica es una de ellas y permite realizar un seguimiento de la proliferación celular tanto in vivo como in vitro en cultivo (4).

La BrdU se utiliza, básicamente, para determinar el comportamiento del ciclo celular y realizar su seguimiento. Para realizar este seguimiento, se tienen en cuenta tanto las diferentes fases del ciclo celular como son G0, G1, S, G2 y M, y ciertos parámetros de la cinética celular como son el tiempo de duplicación de determinada población celular, el tiempo de cada fase, el tiempo total del 
ciclo celular y la fracción de células en crecimiento $(1,2)$. Esta técnica fundamentalmente utiliza la bromodeoxiuridina, un análogo de la timidina, para que se incorpore dentro del ADN en el momento de su replicación, permitiendo así detectar las células que entran en fase S (5) (figura 1).

Según varios autores, el tiempo utilizado para la incorporación de BrdU varía dependiendo del tipo de célula que se utilice y del método que se aplique para la evaluación $(1,4,6)$. Generalmente, en la inmunodetección se emplean anticuerpos marcados con enzimas, isótopos radioactivos, fluorocromos o materiales electrodensos, entre otros $(1,7)$. Además, se realizan inmunocitoquímicas para dos antígenos simultáneamente; el primero de ellos es la BrdU y el segundo incluye marcadores propios de cada tipo celular $(1,8)$.

Para la obtención de resultados óptimos en la aplicación de las técnicas inmunocitoquímicas, es necesario definir las mejores condiciones de procesamiento que garanticen la efectividad y especificidad de la inmunodetección. Así, el objetivo de este trabajo fue definir las condiciones óptimas para la inmunodetección de BrdU incorporada en cultivos celulares.

Con este fin, se tuvieron en cuenta variables de fijación, desnaturalización, diluciones de anticuerpo primario, revelado y tipos celulares, entre otros. Aquí se describe la técnica estandarizada, la cual es aplicable en cualquier tipo de células.

\section{Materiales y métodos}

En la estandarización de la inmunocitoquímica para BrdU, fue necesario ensayar varios parámetros importantes tales como la fijación, la desnaturalización, la neutralización, la dilución del anticuerpo primario y, por supuesto, el revelado $(1,9,10)$, teniendo en cuenta protocolos previos descritos por otros autores $(9,11-18,20)$. El material celular utilizado incluyó fibroblastos de nervios de rata, una línea celular de fibroblastos de riñón de hámster $(\mathrm{BHK})$ y células de Schwann de ganglio de la raíz dorsal de ratón, las cuales se sembraron en cajas de 24 pozos y se dejaron en $\operatorname{BrdU}(5 \mu \mathrm{M})$ durante diferentes períodos de tiempo para posteriormente realizar la inmunocitoquímica con peroxidasa.

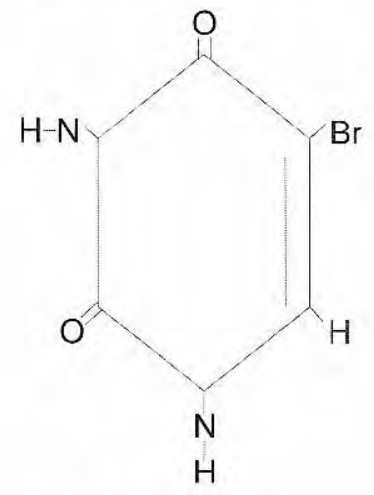

Figura 1. Estructura de la bromodeoxiurina (BrdU).

Las células de ganglio de la raíz dorsal se obtuvieron según la técnica estandarizada en nuestro laboratorio (21-23), que se describe a continuación: se sacrifican los animales por dislocación cervical; se retira la columna vertebral y se obtienen los ganglios ubicados en los espacios intervertebrales. Luego, se realiza una disociación enzimática con colagenasa (150-200 $\mathrm{U} / \mathrm{ml}$ ) durante 2 horas y, posteriormente, una disociación mecánica con la ayuda de una pipeta Pasteur. La suspensión celular obtenida se centrifuga, se resuspende y se siembran de 5.000 a 10.000 células por cubreobjetos previameñte cubiertos con colágeno tipo I, $0,01 \%$ en caja de 24 pozos. Se dejan durante 48 horas en medio DMEM con suero fetal bovino al $10 \%$ (SFB) y los antibióticos penicilina $(100 \mathrm{U} / \mathrm{ml})$, estreptomicina $(100 \mathrm{mg} / \mathrm{ml})$, anfotericina $(0,25 \mu \mathrm{g} / \mathrm{ml})$ y mitógenos (forscolina $2 \mu \mathrm{M}$ y toxina colérica $0,1 \mathrm{mg} / \mathrm{ml}$ ).

Los fibroblastos de nervio se obtuvieron a partir de la disociación directa de nervios ciáticos de ratón, en una mezcla enzimática que contenía dispasa $2 \mathrm{mg} / \mathrm{ml}$ y colagenasa $0,4 \mathrm{mg} / \mathrm{ml}$. Estas células se mantuvieron en DMEM con SFB al $10 \%$ y penicilina $(100 \mathrm{U} / \mathrm{ml})$, estreptomicina $(100 \mathrm{mg} / \mathrm{ml})$ y anfotericina $(0,25 \mu \mathrm{g} / \mathrm{ml})$.

En el caso de la línea celular, las células BHK se mantuvieron en medio DMEM con SFB al 2-5\% y penicilina $(100 \mathrm{U} / \mathrm{ml})$, estreptomicina $(100 \mathrm{mg} / \mathrm{ml})$ y anfotericina $(0,25 \mu \mathrm{g} / \mathrm{ml})$.

A cada tipo celular se le adicionó BrdU $(5 \mu \mathrm{M})$ preparada en el mismo medio de mantenimiento, y se ensayaron tiempos de incorporación de 3, 6, 
24 y 48 horas. El método inmunocitoquímico utilizado y las variables que se tuvieron en cuenta se describen a continuación.

La fijación de las células se hizo con paraformaldehído (PFA) al $4 \%$ preparado en PBS, ensayando tiempos de 15 y 60 minutos y temperaturas de $4{ }^{\circ} \mathrm{C}$ y ambiente. Después se realizaron tres lavados con PBS durante 10 minutos. Para la desnaturalización, paso clave en la técnica, se probaron varias concentraciones de $\mathrm{HCl}$, como son $1,0 \mathrm{~N}, 1,5 \mathrm{~N}$ y $2,0 \mathrm{~N}$, y se dejaron durante 30 minutos. La neutralización se realizó con tetraborato de sodio (Borax) al 0,1 M, pH 8,5 durante 10 minutos a temperatura ambiente; luego, se realizaron tres lavados con el buffer durante 5 minutos. Posteriormente, se permeabilizó con Tritón X-100 preparado al 0,1\% en PBS y se dejó durante 30 minutos a temperatura ambiente. Se lavó con el buffery se inactivó la peroxidasa endógena con $\mathrm{H}_{2} \mathrm{O}_{2}$ al $0,03 \%$ preparado en metanol durante 30 minutos. Se realizó un nuevo lavado con el buffer durante 5 minutos. Se procedió a bloquear los sitios inespecíficos con suero de ternero recién nacido al $10 \%$ en PBS durante 30 minutos. Se incubó en el anticuerpo primario monoclonal anti-Brdu preparado en ratón (IgG pura, DAKO), y se pusieron a prueba varias diluciones desde 1:20 (recomendada por el fabricante) hasta 1:160. Se incubó en el anticuerpo secundario anti-lgG biotinilado de ratón, el cual se dejó durante 30 minutos a temperatura ambiente. Después de cada incubación con cada uno de los anticuerpos, se realizaron tres lavados con el buffer durante 10 minutos cada uno. Luego, se hace una incubación con el complejo avidina-peroxidasa biotinilada. En el revelado se uso la diaminobenzidina (DAB) y, también, el aminoetilcarbazol (AEC) como cromógenos para su posterior aplicación en una doble inmunodetección, los cuales se preparan en una concentración de $0,05 \%$ en tris- $\mathrm{HCl}, \mathrm{pH} 7,2$, cuando se usa DAB como cromógeno. Cuando se usa el AEC como cromógeno, se realiza un lavado con el buffer de revelado y se utiliza una solución que contiene AEC $0,8 \mathrm{mg} / \mathrm{ml}, \mathrm{H}_{2} \mathrm{O}_{2} 0,03 \%$ en buffer acetato de sodio $50 \mathrm{mM}, \mathrm{pH} 5,0$. En ambos casos, la reacción de revelado se detiene por dilución del sustrato de la peroxidasa con agua.

Se usaron dos tipos de control negativo; en uno de ellos se omitió el anticuerpo primario y en el otro se procesó material que no había sido incubado previamente con BrdU.

La contracoloración se realizó con una solución de Hemalun Mayer 1:1 en agua destilada. Finalmente, se continuó con la deshidratación, la cual se realizó con lavados en concentraciones crecientes de etanol de 70 a $100 \%$ durante 5 minutos cada uno y dos lavados con xilol y, por último, se hizo el montaje en Polymount (B) cuando se reveló con $\mathrm{DAB}$. Al utilizar el otro cromógeno (AEC), el montaje se realizó con gelatina de Kaiser, el cual no requiere deshidratación puesto que el AEC es soluble en alcohol y, por tanto, se perdería el revelado.

\section{Resultados}

En este trabajo se estandarizó una técnica de inmunodetección para bromodeoxiuridina en células en cultivo, el cual permitirá determinar el porcentaje de células proliferantes en cultivos celulares.

Para la estandarización, se tuvieron en cuenta diferentes variables con el fin de obtener los mejores resultados.

Para la incorporación se ensayaron tiempos de 3 , 6,24 y 48 horas; en los dos primeros, la tinción observada estuvo presente en pocas células $y$, además, fue de baja intensidad. Con los tiempos mayores, la tinción fue más intensa y la población celular marcada fue numerosa en todos los tipos celulares ensayados. Respecto a la fijación, solamente se probó un fijador y una concentración con diferentes tiempos y temperaturas. Cuando se fijó por corto tiempo ( 15 minutos), tanto a temperatura ambiente como a $4{ }^{\circ} \mathrm{C}$, la preservación morfológica fue deficiente, pues hubo desprendimiento de las células y la morfología, después de todo el procedimiento, presentaba células deformadas con perforaciones en el citoplasma y, en algunos casos, colapso celular. Cuando se realizó la fijación durante períodos de tiempo mayores ( 1 hora) en las diferentes 
temperaturas (temperatura ambiente y $4{ }^{\circ} \mathrm{C}$ ), se observó una buena preservación morfológica. De las dos temperaturas, la fijación a $4^{\circ} \mathrm{C}$ nos permitió obtener la mejor morfología. En todos los casos, la preservación y la estabilidad del antígeno se mantuvo, lo cual permitió su detección.

En la detección de la BrdU como marcador de proliferación, es importante realizar una exposición adecuada de la BrdU mediante la desnaturalización del ADN, que permita el acceso del anticuerpo a su antígeno; así, se ensayaron varias concentraciones de $\mathrm{HCl}$. Cuando se utilizó $\mathrm{HCl} 1 \mathrm{~N}$, no fue posible observar reacción positiva. Con la siguiente concentración, $1,5 \mathrm{~N}$, se observó una tinción tenue. Al usar 2,0 N, la tinción observada fue buena.

Se ensayaron varias diluciones de anticuerpo primario. En la primera dilución, 1:20, se encontró una reacción inespecífica que mostraba positividad tanto en el núcleo como en el citoplasma, además de ser muy intensa. Utilizando una dilución de 1:40, hubo reducción en la intensidad de la reacción, pero fue igualmente inespecífica. Cuando se usó una dilución de 1:80, la inmunorreactividad estuvo restringida a los núcleos y su intensidad fue apropiada. Con la dilución de 1:160, la tinción nuclear no es definida, la intensidad es menor y se observaron citoplasmas marcados.

Para el revelado, se probaron dos cromógenos, $D A B$ y $A E C$; en ambos casos se observó una intensidad buena que contrastaba con la contracoloración.

Teniendo en cuenta los resultados descritos anteriormente, la metodología apropiada para la detección de la BrdU se describe a continuación: se permite la incorporación de BrdU $5 \mu \mathrm{M}$ durante 48 horas, período que cubre el ciclo replicativo de estas células; se lava con el medio de mantenimiento del cultivo durante un mínimo de 3 horas para retirar residuos de BrdU. Las células se fijan con paraformaldehído (PFA) $4 \%$ durante 1 hora a $4^{\circ} \mathrm{C}$ y se realizan tres lavados del fijador con PBS durante 10 minutos; la desnaturalización se hace con $\mathrm{HCl}(2,0 \mathrm{~N})$ durante 30 minutos, seguida por la neutralización con tetraborato de sodio $0,1 \mathrm{M}$, $\mathrm{pH} 8,5$, durante 10 minutos y, posteriormente, se realiza un nuevo lavado en PBS. La permeabilización se hace con una solución de Tritón X-100 en PBS al $0,1 \%$, seguida de tres lavados en PBS, durante $5 \mathrm{~min}$. La inactivación de la peroxidasa endógena se realiza con una solución de $\mathrm{H}_{2} \mathrm{O}_{2}$ $0,03 \%$ en metanol durante 30 minutos: nuevamente se lava en buffer y se bloquean los sitios inespecíficos con suero de ternero recién nacido, $10 \%$, en PBS durante 30 minutos para después hacer la incubación con el anticuerpo primario anti-BrdU (1:80), preparado en la solución de bloqueo a $37{ }^{\circ} \mathrm{C}$ durante 1 hora. Antes y después de la incubación con el anticuerpo secundario biotinilado 1:200 preparado en PBS durante 30 minutos, se hacen tres lavados durante 10 minutos con el buffer; finalmente, se coloca durante 45 minutos el complejo avidina-peroxidasa biotinilada; nuevamente se lava con el buffer y con el buffer de revelado y se revela utilizando una solución $1: 1 \mathrm{de}_{2} \mathrm{O}_{2}$ al $0,02 \%$ /agua destilada y DAB al $0,05 \% /$ tris- $\mathrm{HCl}, \mathrm{pH} \mathrm{7,2,} \mathrm{cuando} \mathrm{se} \mathrm{usa}$ $\mathrm{DAB}$ como cromógeno. Cuando se usa el AEC como cromógeno, se realiza un lavado con el buffer de revelado y se utiliza una solución que contiene AEC $0,8 \mathrm{mg} / \mathrm{ml}, \mathrm{H}_{2} \mathrm{O}_{2} 0,03 \%$ en buffer acetato de sodio $50 \mathrm{mM}, \mathrm{pH} 5,0$. En ambos casos, la reacción de revelado se detiene por dilución del sustrato de la peroxidasa con agua.

Después de la inmunocitoquímica, se apreciaron núcleos rojos cuando se reveló con $\mathrm{AEC}$ (figura $2 A$ ) o núcleos de color café cuando se reveló con $\mathrm{DAB}$ (figura 2B). Estos evidencian las células que incorporaron BrdU y que han pasado por la fase $\mathrm{S}$, los núcleos no inmunorreactivos muestran el color morado de la contracoloración igual a la de los controles negativos (figura $2 \mathrm{C}$ ) y corresponden a las células que no incorporaron BrdU (20). Esta marcación nuclear se observó en ambos tipos celulares en los cultivos de ganglio de la raíz dorsal y en las células de los otros tipos de cultivos.

\section{Discusión}

En la estandarización de la técnica inmunocitoquímica para detectar la incorporación de BrdU, se tuvieron en cuenta varios parámetros. En el caso del tiempo de incorporación, nuestros resultados muestran que con 48 horas, la inmunodetección nos permite ver una tinción nuclear específica y con una intensidad adecuada en los tres tipos celulares ensayados. Este tiempo cubre la fase de síntesis de ADN en estos tipos celulares 

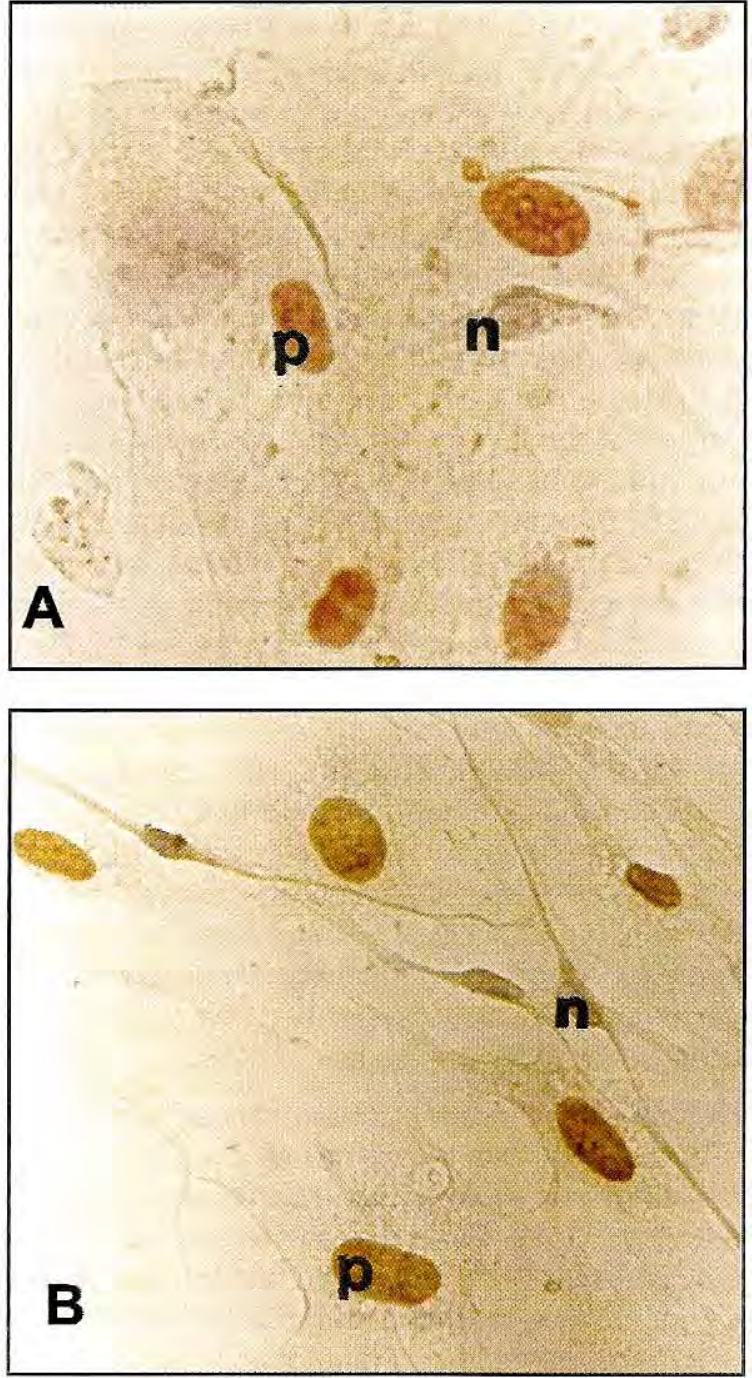

$(21,24-25)$, el cual se debe tener en cuenta para la aplicación de la técnica en otras células.

Otro parámetro que se tuvo en cuenta fue la fijación, que en nuestro caso se realizó con un solo tipo de fijador (PFA), el cual nos garantizó la preservación morfológica y la estabilidad antigénica. El uso de otro tipo de fijadores para el desarrollo de esta técnica, como son el etanol, el metanol y la acetona $(1,9)$, los cuales son agentes desnaturalizantes que permiten la preservación de la BrdU como antígeno, pero que no estabilizan otros antígenos citoplasmáticos, membranales o nucleares y por el contrario los desestabilizan. Estos otros antígenos podrían ser útiles en la

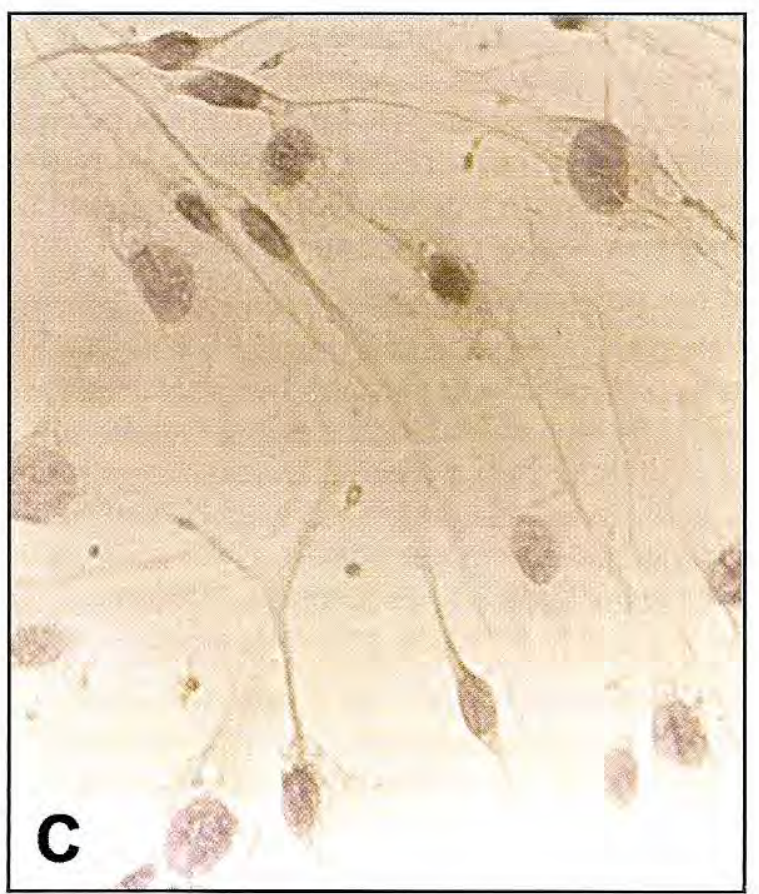

Figura 2. Inmunodetección de BrdU: A) se observan tanto núcleos de color rojizo (positivos, $p$ ), como núcleos morados (negativos, n), utilizando AEC como cromógeno; $B$ ) se observan tanto núcleos café (positivos, p), como morados (negativos, n), utilizando DAB como cromógeno; C) control negativo que muestra núcleos de color morado propios de la contracoloración. (\&) 1.200X.

cuantificación de diferentes tipos celulares o en fases del ciclo celular tanto en cultivos primarios o heterogéneos, que son de nuestro particular interés, o en líneas celulares. Estos serían aplicables en técnicas de doble inmunodetección. Así, el PFA en las condiciones utilizadas nos permite tanto la estabilidad antigénica de la BrdU como de otros antígenos. Por otro lado, el PFA como agente entrecruzante, conserva mejor la morfología, consiguiendo así un buen equilibrio entre la estabilidad antigénica y la preservación morfológica.

Como se mencionó en la metodología y en los resultados, la desnaturalización del $A D N$ es un 
paso fundamental en la detección de la BrdU, puesto que si ésta no es adecuada, el anticuerpo no puede entrar en contacto con su antígeno (1). Se puede usar otro tipo de agentes desnaturalizantes como bases fuertes, enzimas, ácidos y alcoholes, entre otros, dependiendo del procedimiento que se aplique $(6,7,11,13-15,17$ 20). El agente desnaturalizante más ampliamente utilizado en técnicas inmunocitoquímicas es el $\mathrm{HCl}$, el cual proporciona buenos resultados. En nuestro caso la concentración óptima fue de $2,0 \mathrm{~N}$.

De las diluciones ensayadas, la que nos permitió una tinción nuclear específica fue la de 1:80. En las otras diluciones se encontró inespecificidad, ya que presentó reactividad citoplasmática. La dilución óptima dependerá del anticuerpo utilizado.

Finalmente, se probaron dos cromógenos DAB y $A E C$, los cuales nos permiten visualizar la reacción antígeno-anticuerpo (8). Estos cromógenos se utilizaron con el fin de realizar futuros ensayos de doble detección, en los cuales se utiliza la BrdU como marcador de proliferación y simultáneamente marcadores del fenotipo celular. De este modo, es posible escoger un cromógeno adecuado para un procesamiento de doble inmunodetección, el cual es largo y puede ser agresivo, alterando la estabilidad del cromógeno de la primera detección (10).

La metodología tradicional para evaluar la proliferación celular utilizaba radioactividad, la cual constituye un factor de riesgo, además de ser un proceso largo tanto en la incorporación del radiomarcador (timidina tritiada) como en su revelado. Así, el uso de la BrdU y su inmunodetección constituyen una alternativa de fácil manejo y más segura para la evaluación de la proliferación celular y de otras etapas del ciclo celular, tales como G1 o G2-M. De este modo, se puede calcular el tiempo de cada fase y del ciclo celular completo.

Como se mencionó en los materiales y métodos, la técnica se probó inicialmente en otros tipos de células fibroblastos de nervio y una línea celular $\mathrm{BHK}$, en las cuales se obtuvieron excelentes resultados en la detección de células que entran en fase S; por tanto, se considera que la técnica aquí descrita es aplicable a diferentes tipos de cultivos celulares con pequeños ajustes, de acuerdo con el modelo experimental y las necesidades de cada investigador.

\section{Referencias}

1. Dolbeare F. Bromodeoxyuridine: a diagnostic tool in biology and medicine. Part I. Historical perspectives, histochemical methods and cell kinetics. Histochem J 1995;27:339-69.

2. Butler M, Dawson M. Cell culture-Labfax. Oxford: Editorial Bioscientific Publisher Limited; 1992. p.247.

3. Sun-Yong B, Seung U. Proliferation of human Schwann cells induced by new diferentiation factor isoforms. Dev Neurosci 1998;20:512-7.

4. Sondell M, Fex-Svenningsen A, Kanje M. The insuline-like growth factors I and II stimulates. Neuroreport 1997;8:2871-6.

5. Hume WJ, Keat $\mathbf{S}$. Inmunohistological optimization of detection of bromodeoxyuridine-labeled cells in decalcified tissue. J Histochem Cytochem 1990;38:50913.

6. Shun-Fen T, Deiblert G, De Vries G. Myelin basic protein and myelin protein peptides induce the proliferation of Schwann cells via ganglioside GM1and the FGF receptor. Neurochem Res 1999;24:255-60.

7. Cuello AC. Inmunochemistry. Chichester, England: John Wiley \& Sons; 1993. p.456

8. Mason D, Rinok H, French M, Clarke J, Sargent I. Double inmunocytochemical labeling of cell and tissue samples with monoclonal anti-bromodeoxyuridine. J Histochem Cytochem 1989;37:1517-27.

9. Blijham G, Bosman F, Reynders M, Schutte B. Effect of tissue fixation on anti-bromodeoxyuridine inmunohistochemistry. J Histochem Cytochem 1987;35:513435.

10. Hsu M, Soban E. Color modification of diaminobenzinidine (DAB) precipitation by metallic ions and its application for double immunohistochemistry. J Histochem Cytochem 1982;30:1079-82.

11. Gratzner HG. Monoclonal antibody to 5-bromo and 5iododeoxyuridine: a new reagent for detection of DNA replication. Science 1982;218:474-5.

12. Gray JW, Pavinc MC, Gratzner HG, Dolbeare F. Flow cytometric mesaurement of total DNA content and incoroporated bromodeoxyuridine. Proc Natl Acad Sci USA $1983 ; 80,5573-7$

13. De Fasio A, Leary JA, Hedley DW, Tattersal MH. Inmnuhistochemical detection of proliferating cells in vivo. ' Histochem Cytochem 1983;35:571-7.

14. Bravo $\mathbf{M H}$, Bravo R. Evidence of two population of cyclin/proliferating cell nuclear antigen during the cell cycle: association with DNA replication sites. J Cell Biol 1987; 105:1549-54. 
15. Mason DV, Sargent I, Magaud JP. Detection of human cell proliferative responses by inmunoenzymatic measurement of bromodeoxyuridine uptake. J Inmunolog Meth 1988;95:100-6.

16. Berenzney R, Nakayasu H. Mapping replicational sites in the eucaryotic cell nucleus. J Cell Biol 1989;108:1-11.

17. Swütt W, Nebe B, Waldschläger U, Richly J, Kraeft SK. Bromodeoxyuridine distribution patterns in L 929 fibroblasts and influence of tumor necrosis factor. $J$ Histochem Cytochem 1993;35:571-7.

18. Mirsky R, Jessen KR, Louise M, Stweart HJ. Changes in DNA syntesis rate in the Schwann lineage in vivo are correlated with the precursor-Schwann cell transition and myelination. Europ J Neurosci 1993;5,113644.

19. Roy S, Mathur M, Karak AS, Sarkar C, Dinda AK, Kharbanda K. Cell culture studies on human nerves sheath tumors. Pathol 1994;26:29-32.

20. Soames A, Lavender D, Foster J, Williams S, Wheeldon E. Image analysis of bromodeoxyuridine
(BrdU) staining for measurement of S-phase in rat and mouse liver. J Histochem Cytochem 1994;42:939-44.

21. Muñetón VC, Garavito ZV, Hurtado H. Cultivo de células de Schwann, un modelo del microambiente del sistema nervioso. Biomédica 1998:18:45-54.

22. Garavito ZV, Sutachan JJ, Muñetón VC, Hurtado H. Is S-100 a good marker for adult Schwann cell? in vitro cellular and development biology-animal; en prensa.

23. Castellanos E, Hurtado H. Viral infection studied in adult sensory neurons. In: Haynes LW, editor. The neuron in tissue culture. Wiley, England: IBRO Handbook Series: Methods in the Neuroscience; 1999; vol 18. p.289.

24. MacPherson I, Stroker M. Polyoma transformation of Hamster cell clones- an investigation of genetic factors affecting cell competence. Virology 1962;16:47151.

25. Stroker M, MacPherson I. Studies on transformation of Hamster cells by polyoma virus in vitro. Virology 1961:14:359-70. 